\title{
Estimativa das perdas de produção leiteira em vacas mestiças Holandês x Zebu com mastite subclínica baseada em duas metodologias de análise
}

\author{
[Comparison of two methodologies to estimate losses of milk production in crossbred \\ Holstein $x$ Zebu cows with sub-clinical mastitis] \\ H.N. Costa ${ }^{1}$, L.R. Molina ${ }^{2 *}$, C.F.A. Lage ${ }^{1}$, V.M.R. Malacco ${ }^{1}$, \\ E.J. Facury Filho ${ }^{2}$, A.Ú. Carvalho ${ }^{2}$ \\ ${ }^{1}$ Aluno de pós-graduação - Escola de Veterinária - Universidade Federal de Minas Gerais - Belo Horizonte, MG \\ ${ }^{2}$ Escola de Veterinária - Universidade Federal de Minas Gerais - Belo Horizonte, MG
}

\section{RESUMO}

Contagem de células somáticas (CCS) e produção de leite de vacas mestiças Holandês x Gir foram utilizadas para avaliação da perda de produção de leite estimada por duas metodologias, baseadas na CCS média da lactação total encerrada ou na CCS e nas pesagens de leite em diferentes estágios de lactação. Nas primíparas consideradas com mastite subclínica (CCS $\geq 200.000$ células $\mathrm{mL}^{-1}$ ), a perda de produção na lactação total, avaliada pela CCS média da lactação, foi de $814 \mathrm{~kg}$. Para as multíparas, não houve diferença na produção de leite entre vacas com e sem MSC com base na CCS média da lactação. A estimativa avaliada por meio de testes mensais de CCS e pesagens de leite em diferentes estágios de lactação, balanceada pela prevalência de mastite subclínica do mês foi de $917,9 \mathrm{~kg}$ para primíparas e $1178,9 \mathrm{~kg}$ para multíparas. A contraposição da produção de leite com a CCS em diferentes estágios da lactação evidenciou maior perda de produção em relação à observação da CCS média da lactação. A perda de produção de leite de vacas baseada na CCS média de toda a lactação foi subestimada quando comparada à contraposição da produção de leite com CCS em diferentes estágios da lactação.

Palavras-chave: vacas leiteiras, contagem de células somáticas, inflamação, glândula mamária

\begin{abstract}
Somatic cell count (SCC) and milk production of crossbred Holstein x Gir were used to evaluate the estimated loss of milk production two methodologies, based on the average SCC of total closed lactation, or average SCC and weighing milk at different stages of lactation. In primiparous with SCC $m L \geq 200,000$ cells $^{-1}$ production loss in the total lactation, evaluated by the average lactation SCC, was 814 kilograms. For multiparous, there was no difference in milk production between cows with and without SCM based on the SCC media of lactation. The estimate of lost production assessed through monthly testing of SCC and milk weighing at different stages of lactation, balanced by the prevalence of subclinical mastitis, was $917.9 \mathrm{~kg}$ for primiparous and $1178.9 \mathrm{~kg}$ for multiparous. The estimative of milk production with CCS at different stages of lactation showed greater loss of milk production when compared to the estimative based on the average SCC throughout the period of lactation. The milk production loss method based on the average somatic cell count of the whole lactation was underestimated when compared to the method based on average SCC in different stages of lactation.
\end{abstract}

Keywords: milk cows, somatic cell count, inflammation, mammary gland

Recebido em 26 de setembro de 2016

Aceito em 28 de setembro de 2016

*Autor para correspondência (corresponding author)

E-mail: 1molina@vet.ufmg.br 


\section{INTRODUÇÃO}

A mastite subclínica (MSC) acarreta prejuízos econômicos significativos ao produtor, como diminuição da produção e da qualidade do leite, aumento dos custos com tratamento de animais doentes e descarte de animais e do leite dos animais tratados. A MSC não apresenta sinais clínicos aparentes e ocorre com maior prevalência do que a mastite clínica em rebanhos leiteiros (Harmon, 1994; Gianneechini et al., 2002; Cunha et al., 2008), sendo classificada como de longa duração, quando majoritariamente provocada por patógenos contagiosos, ou de curta duração, causada principalmente por microrganismos ambientais (Chaneton et al., 2008). Perdas na produção de leite decorrentes do processo inflamatório que lesiona o parênquima mamário acontecem independentemente do microrganismo presente na glândula mamária (Hand, 2012; Harmon, 1994).

Diversas pesquisas definem como vacas sadias aquelas com CCS $<200.000$ células $\mathrm{mL}^{-1}$ e vacas com MSC aquelas com CCS $\geq 200.000$ células $\mathrm{mL}^{-1}$ (Dohoo e Leslie, 1991; Akers e Nickerson, 2011; Dufour e Dohoo, 2013; Ruegg e Pantoja, 2013).

Para aplicação de estratégias de controle e monitoramento da qualidade do leite em rebanhos leiteiros, a adoção do uso de amostras compostas é um método prático e factível na maioria das situações. Mesmo considerando a possibilidade de alguns animais serem falsonegativos, Harmon (1994) estabeleceu que $80 \%$ dos animais com CCS $<200.000$ células $\mathrm{mL}^{-1}$ estão sadios.

A perda de produção de leite em 305 dias, associada ao aumento da contagem média de células somáticas na lactação de vacas leiteiras, foi estimada em pesquisa pioneira por Raubertas e Shook (1982), que passou a ser o método convencionalmente utilizado por pesquisadores para estimar perdas de produção leiteira decorrentes da MSC.

Segundo Hagnestam-Nielsen et al. (2009), a perda na produção de leite devido à MSC deve ser estimada levando-se em consideração a CCS em diferentes estágios da lactação e não a CCS média da lactação encerrada, que pode levar a valores subestimados. Isso ocorreria porque os picos na CCS devido às infecções de curta duração, causadas especialmente por microrganismos ambientais (Chaneton et al., 2008), seriam desconsiderados pela análise convencional proposta por Raubertas e Shook (1982).

Revisões da literatura e estudos de meta-análises têm abordado a perda de produção de leite devido ao aumento da CCS, tanto para o dia do teste e a fase da lactação quanto para as lactações encerradas (Seegers et al., 2003; Halasa et al., 2007). No entanto, existem lacunas a respeito da perda de produção para vacas mestiças manejadas em condições brasileiras.

Diante desse cenário, objetivou-se estimar as perdas de produção de leite de vacas mestiças devido à MSC utilizando-se duas metodologias de análise.

\section{MATERIAL E MÉTODOS}

Todos os procedimentos utilizados foram aprovados pelo Comitê de Ética (Cetea 117/2011) da UFMG. O estudo foi realizado em uma propriedade leiteira situada na região centro-oeste de Minas Gerais. A região possui clima tropical de altitude com verões quentes, temperatura média anual de $21,8^{\circ} \mathrm{C}$, temperatura mínima de $7^{\circ} \mathrm{C}$ no inverno e máxima de $35^{\circ} \mathrm{C}$ no verão, com umidade relativa do ar máxima de $74,8 \%$ e precipitação pluviométrica anual de $1657 \mathrm{~mm}$, de acordo com dados históricos da fazenda. $\mathrm{O}$ rebanho era composto por vacas mestiças 3/4, 5/8, 7/8 e 15/16 Holandês x Gir. A média de produção de leite diária por animal durante o período experimental foi de $16,5 \mathrm{~kg}$. O sistema de produção de leite da fazenda era semiintensivo, no qual os animais permaneciam em pastagem na estação chuvosa e recebiam suplementação volumosa em pistas de alimentação no período seco. $\mathrm{O}$ experimento iniciou-se com 90 animais em lactação e terminou com 125 vacas, sendo 183 o máximo de animais ordenhados no período experimental nos 17 meses de análise. As vacas eram ordenhadas duas vezes ao dia, às cinco e às 16 horas. Todos os procedimentos de rotina de ordenha, limpeza e manutenção do equipamento de ordenha eram feitos de acordo com o preconizado no NMC (Laboratory..., 1999). 
Durante o período de estudo, coletaram-se mensalmente amostras de leite compostas e individuais, destinadas à análise da CCS, iniciando-se no $10^{\circ}$ dia de lactação, segundo o protocolo do NMC (Laboratory..., 1999). As amostras $(50 \mathrm{~mL})$ foram retiradas diretamente de medidores de leite acoplados ao equipamento de ordenha e acondicionadas em frascos contendo bronopol (2-bromo-2-nitropropano-1,3-diol), permitindo sua conservação à temperatura ambiente. As amostras foram homogeneizadas por inversão do frasco até a completa dissolução do comprimido e enviadas ao Laboratório de Análise da Qualidade do Leite da Escola de Veterinária da UFMG (LabUFMG®, Belo Horizonte, MG, Brasil). As análises de CCS foram realizadas pelo método eletrônico em equipamento Bentley® (Bentley Instruments Incorporated - Minneapolis, EUA).

O banco de dados foi construído com dados da CCS individual das vacas, produção de leite diária registrada semanalmente, lactação total encerrada, dias em lactação (DEL) e ordem de parto registrados no software Prodap ${ }^{\circledR}$ (Prodap Belo Horizonte, MG, Brasil). Durante os 17 meses de estudo, foram avaliadas 1763 amostras de CCS e sua relação com as variáveis descritas anteriormente, sendo 1054 amostras de vacas multíparas e 709 de vacas primíparas. Foram considerados animais com MSC os que apresentavam CCS maior ou igual a 200.000 células $\mathrm{mL}^{-1}$ e sem MSC aqueles com CCS menor que 200.000 células $\mathrm{mL}^{-1}$. Animais com alterações no leite, típicas de mastite clínica (grumo, sangue e/ou leite aquoso), não eram analisados no mês da ocorrência. As análises de variância para produção de leite e CCS foram realizadas pelo PROC MIXED do programa estatístico SAS (SAS, 2002-2003) considerandose a vaca como efeito aleatório (medida repetida). Foram avaliados os efeitos fixos de ano do parto, mês do parto ou época do ano, grupamento genético e ordem de parto (primíparas e multíparas).

Para a CCS, foi incluído no modelo o efeito da covariável dias em lactação. A variável CCS foi transformada em logaritmo na base 10 , por não apresentar distribuição normal.
Utilizou-se o seguinte modelo estatístico:

$\mathrm{Y}_{\mathrm{ijklm}}=\mu+\mathrm{V}_{\mathrm{i}}+\mathrm{GG}_{\mathrm{j}}+\mathrm{OP}_{\mathrm{k}}+\mathrm{Est}_{\mathrm{l}}+\mathrm{Ano}_{\mathrm{m}}+(\mathrm{OP}$

$\mathrm{x}$ Ano $)_{\mathrm{km}}+\mathrm{e}_{\mathrm{ijklm}}$,

em que:

$\mu$ : média geral;

$\mathrm{V}_{\mathrm{i}}$ : efeito de vaca;

$\mathrm{GG}_{\mathrm{j}}$ : efeito de grupamento genético;

$\mathrm{OP}_{\mathrm{k}}$ : efeito da ordem de parto;

Est $_{1}$ : efeito da estação do ano (verão e inverno);

$\mathrm{Ano}_{\mathrm{m}}$ : efeito do ano do parto;

$(\mathrm{OP} \times \mathrm{Ano})_{\mathrm{km}}$ : efeito da interação ordem de parto e ano do parto;

$\mathrm{e}_{\mathrm{ijklm}}$ : erro associado a cada observação.

O efeito da CCS sobre a perda de produção de leite foi avaliado utilizando-se duas metodologias, seguindo o mesmo modelo estatístico descrito acima.

Pelo método convencional, avaliou-se a CCS média na lactação e a respectiva produção de leite, comparando-se vacas sem MSC e vacas com MSC. Nessa análise, a perda de produção de leite no grupo com mastite subclínica foi calculada pela diferença entre a produção leiteira dos grupos sem e com MSC (Raubertas e Shook, 1982). As diferenças foram consideradas significativas quando $\mathrm{P}<0,05$.

A outra análise foi realizada utilizando-se a metodologia proposta por Hagnestam-Nielsen $e t$ al. (2009), em que se avaliou o efeito da CCS sobre a produção de leite ao longo da lactação das vacas, isto é, foi observado o efeito da MSC sobre a produção de leite em cada mês. Dessa forma, no mesmo dia em que se coletava amostra do leite para CCS, também era pesado o leite total produzido por animal. Foram criadas 12 fases de lactação com intervalo de 30 dias, iniciando-se no dia zero pós-parto até a secagem. A estimativa de perda mensal de produção associada ao aumento da CCS foi calculada pelo uso de equações de regressão e seus respectivos coeficientes em cada fase de lactação, tanto para primíparas quanto para multíparas. A perda mensal de leite considerou a prevalência da MSC no rebanho naquela fase da lactação e a estimativa de perda de leite foi calculada pela diferença entre a produção das vacas com e sem MSC. A perda da produção de leite na lactação 
total foi calculada pela soma das estimativas de perdas mensais de produção das vacas com MSC. Para cálculo dos coeficientes de regressão, foi feita análise de regressão linear simples pelo PROC REG do programa SAS (SAS, 2003).

\section{RESULTADOS E DISCUSSÃO}

Os dados da perda de produção de leite estimada pelo método convencional estão apresentados na Tab. 1. Vacas primíparas com MSC tiveram perda na produção de leite quando comparadas com primíparas sem MSC, sendo da ordem de $15,2 \%$ (814kg de leite) (Tab. 1). Não houve diferença na produção de leite $(\mathrm{P}>0,05)$ entre vacas multíparas com e sem MSC. Os resultados encontrados neste trabalho para a metodologia convencional não eram esperados, uma vez que maiores perdas são esperadas em multíparas que em primíparas, devido às exposições prévias e consequentemente aos danos permanentes na glândula mamária (Hand, 2012). A magnitude das perdas encontradas foi diferente das observadas por Raubertas e Shook (1982), em que as primíparas perderam em média $135 \mathrm{~kg}$ de leite na lactação, e as multíparas $270 \mathrm{~kg}$ utilizando-se a mesma metodologia. A prevalência de microrganismos contagiosos na propriedade, no período de realização do presente estudo, era de $6 \%$, como mostrado em trabalho desta mesma equipe anteriormente (Costa et al., 2015). A baixa incidência de infecções por agentes contagiosos pode ter influenciado na ausência de perda de produção em vacas multíparas para essa metodologia de análise.

Tabela 1. Efeito da CCS sobre a produção de leite de vacas primíparas e multíparas estimado pelo método convencional, de acordo com Raubertas e Shook (1982)

\begin{tabular}{lcc}
\hline & \multicolumn{2}{c}{ Produção de leite na lactação $(\mathrm{kg})$} \\
\cline { 2 - 3 } CCS & Primíparas & Multíparas \\
\hline$<200 \mathrm{mil}$ & $5324 \mathrm{aA}$ & $5692 \mathrm{aA}$ \\
$\geq 200 \mathrm{mil}$ & $4510 \mathrm{aB}$ & $5588 \mathrm{bA}$ \\
\hline
\end{tabular}

Médias seguidas de letras distintas, minúsculas nas linhas e maiúsculas nas colunas, diferem estatisticamente pelo teste de $\mathrm{t}(\mathrm{P}<0,05)$.

Segundo Hagnestam-Nielsen et al. (2009), ao se analisar a perda de produção de leite com base na média da CCS na lactação total, podem ser perdidos picos de CCS que afetam a perda na produção de leite naquele momento, o que levaria a um resultado final subestimado. Para esses pesquisadores, isso aconteceria principalmente no caso de MSC causada por microrganismos ambientais e oportunistas que, de acordo com Chaneton et al. (2008), geralmente geram infecções de curta duração. A utilização de uma metodologia que leve em consideração esses picos de CCS é especialmente importante em sistemas em que se tem alta susceptibilidade a microrganismos ambientais. Diferentemente das condições avaliadas em muitos trabalhos, nos quais o risco de infecções por microrganismos ambientais é mais pronunciado no período chuvoso, os sistemas semi-intensivos propiciam acúmulo de matéria orgânica e, consequentemente, aumento da umidade no ambiente durante o período seco, que mantêm alto o risco de infecção.

Os coeficientes de regressão da produção diária de leite e os dados da perda de produção de leite estimada pelo método proposto por HagnestamNielsen et al. (2009) para multíparas e primíparas estão apresentados nas Tab. 2, 3 e 4, respectivamente.

A perda de produção de leite estimada de acordo com a proposta de Hagnestam-Nielsen et al. (2009) foi influenciada pela fase de lactação em vacas com MSC (Tab. 2) e apresentou o mesmo padrão para multíparas (Tab. 3) e primíparas (Tab. 4), sendo mais intensa com o avanço da lactação. A estimativa diária da perda de produção para vacas multíparas com MSC, durante toda a lactação, foi de 3,5kg/dia (Tab. 3). Neste estudo, considerando a perda diária de leite em cada fase da lactação, observou-se diminuição de $20,7 \%$ na lactação de vacas multíparas com MSC em relação às sadias. A diferença da perda de produção de leite observada nas duas metodologias utilizadas pode ser explicada pelos picos de CCS (Fig. 1) que ocorreram durante toda a lactação, evidenciando mais intensamente as perdas pontuais. Segundo De Haas et al. (2002), a CCS se comporta de forma diferente para cada patógeno e em infecções de curta duração retorna aos valores normais rapidamente. $\mathrm{Na}$ estimativa de perda da produção utilizando-se a CCS média da lactação, esses picos não seriam evidenciados, subestimando a perda. 
Tabela 2. Coeficientes de regressão da produção diária de leite de vacas primíparas e multíparas (transformada em $\log 10$ ), baseados nos testes mensais de pesagem de leite e CCS

\begin{tabular}{lllllllllllllll} 
Dias & 0 a 30 & 31 a 60 & 61 a 90 & 91 a 120 & 121 a 150 & 151 a 180 & 181 a 210 & 211 a 240 & 241 a 270 & 271 a 300 & 301 a 330 & $>330$ \\
\hline $\begin{array}{l}\text { Primíparas } \\
\text { linear }-2,1^{*}\end{array}$ & $-1,7^{*}$ & $-1,2^{* *}$ & $-1,89^{*}$ & $-1,2^{\mathrm{NS}}$ & $-3,0^{*}$ & $-1,0^{\mathrm{NS}}$ & $-3,23^{*}$ & $-3,46^{*}$ & $-2,7^{*}$ & $-2,7^{*}$ & $-3,6^{*}$ \\
$\begin{array}{l}\text { Multíparas } \\
\text { linear }-1,05^{\mathrm{NS}}\end{array}$ & $-1,8^{*}$ & $-2,5^{*}$ & $-2,6^{*}$ & $-2,3^{*}$ & $-3,9^{*}$ & $-3,4^{*}$ & $-3,2^{*}$ & $-2,4^{* *}$ & $-4,0^{*}$ & $-5,35^{*}$ & $-4,2^{*}$ \\
\hline
\end{tabular}

${ }^{*} \mathrm{P}<0,01 ;{ }^{* *} \mathrm{P}<0,05 ;$ NS: não significativo.

Tabela 3. Perda absoluta de leite diária e mensal $(\mathrm{kg})$ em diferentes estágios da lactação de vacas multíparas, expressa como desvio da quantidade de leite produzido das vacas com CCS $\geq 200$ mil e vacas com CCS < 200 mil, e prevalência de mastite subclínica

\begin{tabular}{|c|c|c|c|c|}
\hline Dias em lactação & Del $^{1}$ Médio & $\begin{array}{c}\text { Estimativa da perda } \\
\text { de leite } \\
(\mathrm{kg} / \text { dia })^{2} \\
\end{array}$ & $\begin{array}{c}\text { Prevalência mastite } \\
\text { subclínica } \\
(\%) \\
\end{array}$ & $\begin{array}{c}\text { Estimativa da perda de } \\
\text { produção } \\
\text { (kg/mês) }\end{array}$ \\
\hline 0 a 30 & 13,4 & $1,37 *$ & $39 \%$ & 15,9 \\
\hline 31 a 60 & 44,6 & $2,16^{*}$ & $37 \%$ & 23,8 \\
\hline 61 a 90 & 71,1 & $2,95^{*}$ & $39 \%$ & 34,1 \\
\hline 91 a 120 & 104,2 & $3,63^{*}$ & $59 \%$ & 63,8 \\
\hline 121 a 150 & 134,5 & $3,20 *$ & $53 \%$ & 51,2 \\
\hline 151 a 180 & 163,8 & $5,49 *$ & $67 \%$ & 109,9 \\
\hline 181 a 210 & 194,8 & $4,38 *$ & $57 \%$ & 74,2 \\
\hline 211 a 240 & 228,1 & $3,48^{*}$ & $57 \%$ & 59,2 \\
\hline 241 a 270 & 253,5 & $2,35^{*}$ & $76 \%$ & 53,9 \\
\hline 271 a 300 & 286,6 & $3,98 *$ & $62 \%$ & 74,4 \\
\hline 301 a 330 & 320,3 & $5,35^{*}$ & $64 \%$ & 103,2 \\
\hline 331 a 566 & 450,3 & $3,80 *$ & $58 \%$ & 515,3 \\
\hline Média & & 3,5 & $56 \%$ & \\
\hline Total de leite & & & & 1178,9 \\
\hline
\end{tabular}

\section{$* \mathrm{P}<0,05$.}

${ }^{1}$ Dias em lactação. ${ }^{2}$ Média de produção de leite das vacas com CCS $\geq 200$ mil subtraída da produção de leite de vacas com CCS <200 mil.

Tabela 4. Perda absoluta de leite diária e mensal $(\mathrm{kg})$ em diferentes estágios da lactação de vacas primíparas, expressa como desvio da quantidade de leite produzido por vacas com CCS $\geq 200$ mil e vacas com CCS < 200 mil, e prevalência de mastite subclínica

\begin{tabular}{|c|c|c|c|c|}
\hline $\begin{array}{ll}\text { Dias } & \text { em } \\
\text { lactação } & \end{array}$ & $\begin{array}{l}D_{\text {Del }}^{1} \\
\text { médio }\end{array}$ & $\begin{array}{l}\text { Estimativa da perda de leite } \\
(\mathrm{kg} / \mathrm{dia})^{2}\end{array}$ & $\begin{array}{ll}\begin{array}{l}\text { Prevalência } \\
\text { subclínica }(\%)\end{array} & \text { mastite } \\
\end{array}$ & $\begin{array}{l}\text { Estimativa da perda de produção } \\
\text { (kg/mês) }\end{array}$ \\
\hline 0 a 30 & 13,4 & $2,30 *$ & $39 \%$ & 26,9 \\
\hline 31 a 60 & 44,6 & $2,80 *$ & $16 \%$ & 13,4 \\
\hline 61 a 90 & 71,1 & $1,97 *$ & $11 \%$ & 6,5 \\
\hline 91 a 120 & 104,2 & $2,84 *$ & $20 \%$ & 17,0 \\
\hline 121 a 150 & 134,5 & $1,44^{*}$ & $22 \%$ & 9,5 \\
\hline 151 a 180 & 163,8 & $3,58 *$ & $27 \%$ & 29,0 \\
\hline 181 a 210 & 194,8 & $1,48 *$ & $29 \%$ & 12,9 \\
\hline 211 a 240 & 228,1 & $5,25 *$ & $23 \%$ & 36,2 \\
\hline 241 a 270 & 253,5 & $3,81 *$ & $28 \%$ & 32,0 \\
\hline 271 a 300 & 286,6 & $3,76 *$ & $40 \%$ & 45,1 \\
\hline 301 a 330 & 320,3 & $4,31 *$ & $41 \%$ & 53,0 \\
\hline 331 a 600 & 450,3 & $3,80 *$ & $46 \%$ & 636,3 \\
\hline Média & & 3,1 & $29 \%$ & \\
\hline Total & & & & 917,9 \\
\hline
\end{tabular}

$* \mathrm{P}<0,05$.

${ }^{1}$ Dias em lactação. ${ }^{2}$ Média de produção de leite das vacas com CCS $\geq 200$ mil subtraída da produção de leite de vacas com CCS $<200$ mil. 


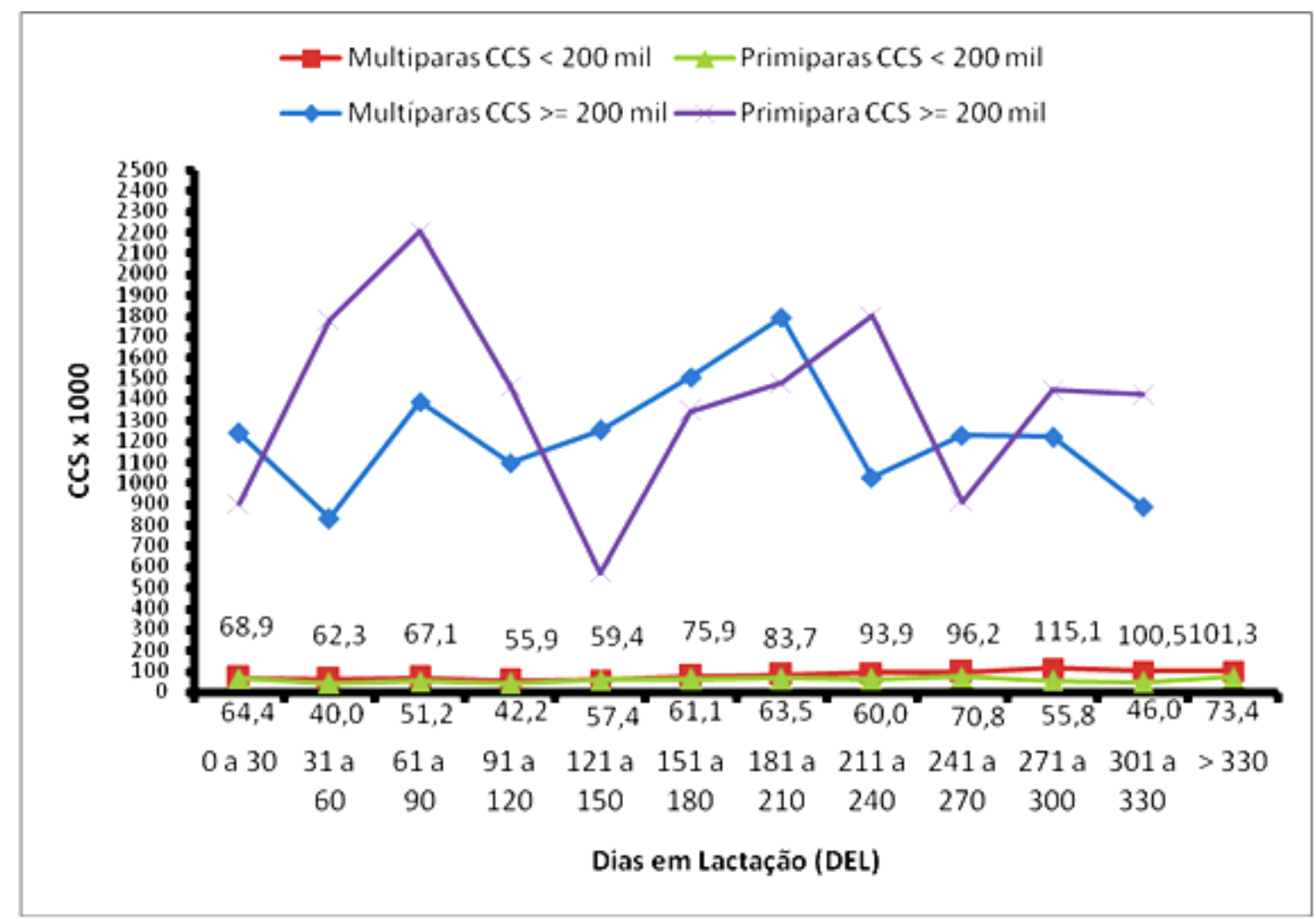

Figura 1. Contagem de células somáticas de vacas primiparas e múltiparas com e sem MSC, em diferentes estágios de lactação.

A estimativa da perda de produção diária de leite nas vacas primíparas com MSC durante toda lactação foi de $3,1 \mathrm{~kg}$ (Tab. 4). A metodologia convencional subestimou em $103,9 \mathrm{~kg}$ a perda de produção de leite para primíparas com MSC comparada à metodologia de análise mensal.

No grupo de primíparas, a redução na produção de leite de vacas com MSC estimada pela metodologia de análise mensal foi de $17,2 \%$. A estimativa da perda de produção de leite nos primeiros 60 dias de lactação foi de 20,2 e $19,9 \mathrm{~kg}$ de leite, e após 61 dias de lactação foi de 48,9 e 70,6kg de leite (Tab. 3 e 4), para primíparas e multíparas, respectivamente. A maior perda na lactação pela MSC ocorreu com o avançar dos DEL das vacas. Hortet et al. (1999) afirmaram que a alta CCS contribui para maior perda de leite no final da lactação devido ao efeito cumulativo de infecções na glândula mamária ao longo da lactação. HagnestamNielsen et al. (2009) relatam que o úbere no final da lactação está em estado catabólico, ou seja, devido a mudanças hormonais que favorecem a gestação em detrimento da lactação (maior insulina, menor GH), a glândula tem menor habilidade de repor células danificadas, se comparado ao início da lactação, quando está hormonalmente em estado anabólico, que favorece a reparação tecidual (alto GH, IGF1, prolactina). Os autores relatam que, embora a perda de produção de leite em quartos mamários com MSC seja geralmente considerada constante na maioria dos estudos, no início da lactação a capacidade de regeneração da glândula mamária é maior devido ao seu estado anabólico, compensando a lesão tecidual e consequentemente mascarando a perda na produção.

Utilizando-se a metodologia convencional, não foi observada perda de produção nas vacas multíparas com MSC, contrariando o que foi observado pela metodologia que considera a avaliação mensal. Nessa metodologia, a perda na produção foi expressiva e maior na fase final da lactação, sendo a produção das multíparas com MSC significativamente mais comprometida que das primíparas com MSC. Maiores perdas de produção por MSC são geralmente descritas em 
vacas multíparas do que em primíparas (Reneau, 1986; Hand, 2012). Segundo Bartlett et al. (1990), pior saúde do úbere é mais esperada em multíparas que em primíparas e, no final da lactação, em ambas as categorias. Isso poderia ser explicado devido a exposições prévias a patógenos causadores de mastite que poderiam causar danos permanentes à glândula mamária.

Hagnestam-Nielsen et al. (2009) encontraram uma redução na produção de leite de $155 \mathrm{~kg}$ de leite na lactação total de primíparas e de $455 \mathrm{~kg}$ para vacas multíparas, perdas menores do que as encontradas no presente trabalho. Outros trabalhos realizados nos EUA também encontraram perdas menores (Holland et al., 2015). Coldebella et al. (2004), ao estudarem vacas Holandesas confinadas no Brasil, encontraram perdas de $1092 \mathrm{~kg} /$ lactação para multíparas e de $270 \mathrm{~kg} / \mathrm{lactação} \mathrm{para} \mathrm{primíparas.}$ Esses resultados indicam que, em condições de alto risco de infecção por microrganismos ambientais, as perdas em produção de leite são muito altas, reforçando a importância de medidas de controle que reduzam esses fatores de risco.

Tanto nas primíparas quanto nas multíparas sem MSC, a média da CCS manteve-se abaixo de 120.000 células $\mathrm{mL}^{-1}$, com ligeiro aumento à medida que a lactação avançava. Vários autores (Wiggans e Shook, 1987; Harmon, 1994; De Vliegher et al., 2004; Breen et al., 2009; Ten Napel et al., 2009) encontraram resposta com efeito quadrático da CCS e estágio da lactação com menor valor de CCS no pico de lactação e aumento até o final desta, porém com contagens sempre abaixo de 200.000 células $\mathrm{mL}^{-1}$.

\section{CONCLUSÃO}

A perda de produção de leite de vacas baseada na contagem de células somáticas média de toda a lactação (metodologia convencional) é subestimada quando comparada à contraposição da produção de leite com CCS em diferentes estágios da lactação. A magnitude da perda de produção diária associada à MSC, na metodologia de avaliação mensal, é relacionada ao estágio da lactação e à ordem de parto, apresentando-se mais expressiva ao final da lactação, independentemente da ordem de parto e significativamente maior para multíparas.

\section{REFERÊNCIAS}

AKERS, R.M.; NICKERSON, S.C. Mastitis and its impact on structure and function in the ruminant mammary gland. J. Mammary Gland Biol. Neoplasia, v.16, p.275-289, 2011.

BARTLETT, P.C.; MILLER, G.Y.; ANDERSON, C.R. et al. Milk production and somatic cell count in Michigan dairy herds. $J$. Dairy Sci., v.73, p.2794-2800, 1990.

BREEN, J.E.; BRADLEY, A.J.; GREEN, M.J. Quarter and cow risk factors associated with a somatic cell count greater than 199,000 cells per milliliter in United Kingdom dairy cows. $J$. Dairy Sci., v.92, p.3106-3115, 2009.

CHANETON, L.; TIRANTE, L.; MAITO, J. et al. Relationship between milk lactoferrin and etiological agent in the mastitic bovine mammary gland. J. Dairy Sci., v.91, p.1865-1873, 2008.

COLDEBELLA, A.; MACHADO, P.F.; DEMÉTRIO, C.G.B. et al. Contagem de células somáticas e produção de leite em vacas holandesas confinadas. Rev. Bras. Zootec., v.33, p.623-634, 2004.

COSTA, H.N.; MOLINA, L.R.; FACURY FILHO E.J. et al. Longitudinal study of subclinical mastitis and milk production on crossbred Holstein $x$ Zebu cattle, housed in a semi-intensive system. Arq. Bras. Med. Vet. Zootec., v.67, p.1501-1509, 2015.

CUNHA, R.P.L.; MOLINA, L.R.; CARVALHO, A.U. et al. Mastite subclínica e relação da contagem de células somáticas com número de lactações, produção e composição química do leite em vacas da raça Holandesa. Arq. Bras. Med. Vet. Zootec., v.60, p.19-24, 2008.

DE HAAS, Y.; BARKEMA, H.W.; VEERKAMP, R.F. The effect of pathogenspecific clinical mastitis on the lactation curve of somatic cell count. J. Dairy Sci., v.85, p.13141323, 2002.

DE VLIEGHER, S.; BARKEMA, A.W.; STRYHN, H. et al. Impact of early lactation somatic cell count in heifers on somatic cell counts over the first lactation. J. Dairy Sci., v.87, p.3672-3682, 2004. 
DOHOO, I.R.; LESLIE K.E. Evaluation of changes in somatic cell counts as indicators of new intramammary infections. Prev. Med. Vet., v.10, p.225-237, 1991.

DUFOUR, S.; DOHOO, I.R. Monitoring herd incidence of intramammary infection in lactating cows using repeated longitudinal somatic cell count measurements. J. Dairy Sci., v.96, p.15681580, 2013.

GIANNEECHINI, R.; CONCHA, C.; RIVERO, $\mathrm{R}$. et al. Occurrence of clinical and subclinical mastitis in dairy herds in the west littoral region in Uruguay. Acta Vet. Scand., v.43, p.221-230, 2002.

HAGNESTAM-NIELSEN, C.; EMANUELSON, U.; BERQLUND, B. et al. Relationship between somatic cell count and milk yield in different stages of lactation. J. Dairy Sci., v.92, p.31243133, 2009.

HALASA, T.; HUIJPS, K.; OSTERAS, O. et al. Economic effects of bovine mastitis and mastitis management: a review. Vet. Q., v.29, p.18-31, 2007.

HAND, K.J. Milk production and somatic cell counts: a cow-level analysis. J. Dairy Sci., v.95, p.1358-1362, 2012.

HARMON, R.J. Physiology of mastitis and factors affecting somatic cell counts. J. Dairy Sci., v.77, p.2103-2112, 1994.

HOLLAND, J.K.; HADRICH, J.C.; WOLF, C.A.; LOMBARD, J. Economics of measuring costs due to mastitis-related milk loss. In: ANNUAL MEETING, 2015, San Francisco. Proceedings... San Francisco: Agricultural and Applied Economics Association \& Western Agricultural Economics Association, 2015. (No. 205638).
HORTET, P.; BEAUDEAU, F.; SEEGERS, H. et al. Reduction in milk yield associated with somatic cell counts up to 600.000 cells $/ \mathrm{mL}$ in French Holsteins cows without clinical mastitis. Livest. Prod. Sci., v.61, p.33-42, 1999.

LABORATORY handbook on bovine mastitis. [New Prague]: Madison National Mastitis Council, 1999. 222p.

RAUBERTAS, R.F.; SHOOK, G.E. Relationship between lactation measures of somatic cell concentration and milk yield. J. Dairy Sci., v.65, p.419-425, 1982.

RENEAU, J.K. Effective use of dairy herd improvement somatic cell counts in mastitis control. J. Dairy Sci., v.69, p.1708-1720, 1986.

RUEGG, P.L., PANTOJA, J.C.F. Understanding and using somatic cell counts to improve milk quality. Irish. J. Agric. Food. Res., v.52, p.101$117,2013$.

SAS user's guide: statistics. Version 9.1 for Windows. Cary: SAS Inst., 2003.

SEEGERS, H.; FOURICHON, C.; BEAUDEAU.F. Production effects related to mastitis and mastitis economics in dairy cattle herds. Vet. Res., v.34, p.475-491, 2003.

TEN NAPEL, J. Characterization of distributions of somatic cell counts. J. Dairy Sci., v.92, p.1253-1264, 2009.

WIGGANS, G.R.; SHOOK, G.E. A lactation measure of somatic cell count. J. Dairy Sci., v.70, p.2666-2672, 1987. 